\title{
La diversidad paisajista en el estado de Chiapas, México
}

\author{
Horacio Morales Iglesias $^{1}{ }^{\text {| Ángel Guadalupe Priego Santander }}{ }^{2}$
}

Recibido: 08/03/2019 | Aceptado: 14/05/2019

\section{Resumen}

El objetivo de la presente investigación es conocer y evaluar la distribución de la complejidad y diversidad de los paisajes físico-geográficos del estado de Chiapas, México. Para cumplir con este objetivo se aplicaron dos índices de complejidad, uno de riqueza y dos de diversidad geoecológica al mapa de los paisajes físico-geográficos del estado de Chiapas, a escala 1: 250000. Los resultados indican una coincidencia espacial entre la diversidad y la complejidad paisajista. Los niveles alto y muy alto de esta correlación son representados por una minoría de extensos paisajes de origen tectónico-kárstico, tectónico-acumulativo y tectónico-intrusivo; las regiones físico-geográficas con estos tipos de paisajes son Sierra Lacandona, Sierras del Norte de Chiapas y Sierras del Sur de Chiapas.

Las investigaciones sobre heterogeneidad geoecológica bajo el enfoque de la Geografía Física Compleja generan relevantes contribuciones a la Planificación Territorial, debido a que los resultados permiten identificar de manera clara y objetiva las áreas con mayor geodiversidad.

Palabras clave: paisaje; riqueza; complejidad; geodiversidad; Chiapas

\section{Abstract \\ Landscape diversity in the Chiapas State, Mexico}

The goal of this research is to understand and evaluate the distribution of the complexity and heterogeneity of the physical-geographical landscapes of Chiapas, Mexico. In order to achieve this goal, two indicators of complexity, one of richness and two of geoecological diversity, were applied to the map of the physical-geographical landscapes of the Chiapas State, in a 1: 250000 scale. The results indicate a spatial coincidence between diversity and complexity landscape. The high and very high levels of this correlation are represented by a minority of extensive landscapes of tectonic-karstic, tectonic-accumulative and tectonic-intrusive origin; the physical-geographical regions with these kinds of landscapes are Sierra Lacandona, Sierras del Norte de Chiapas and Sierras del Sur de Chiapas.

The researchs about geoecological heterogeneity through the Complex Physical Geography approach generate relevant contributions to the Land-use planning studies, because the results allow clearly and objectively to identify the areas with the greatest geodiversity.

Keywords: landscape; richness; complexity; geodiversity; Chiapas

1. Instituto de Investigación en Gestión de Riesgos y Cambio Climático. UNICACH. Tuxtla Gutiérrez, Chiapas, México. horacio. morales@unicach.mx

2. Centro de Investigaciones en Geografía Ambiental, UNAM campus Morelia, Michoacán, México. apriego@ciga.unam.mx 


\section{Introducción}

Los estudios geográficos bajo una aproximación paisajista representan una valiosa alternativa en la solución de los problemas ambientales, debido a que generan un análisis holístico e integral del territorio. Actualmente, en el marco de una severa crisis ambiental, el paisaje tiene una elevada injerencia en dos estrategias que ha establecido la sociedad para conservar el planeta: la biodiversidad y la geodiversidad. En este sentido, la primera considera al paisaje dentro de la diversidad biológica a nivel gama (Turner and Gardner, 1991; Moreno, 2001);específicamente dentro del enfoque biocéntrico de la Ecología del Paisaje, mientras que la segunda adopta el marco teórico de éste, para explicar condiciones de estructura y funcionalidad (Kozlowski, 2004), logrando una diferenciación integral (policéntrica) de las unidades de la superficie terrestre, considerando todos los componentes naturales, o sea, el geólogo-geomorfológico, el hidro-climático y el edafobiógeno, es decir, la geoecología del paisaje (Priego et al., 2013).

Por lo anterior, la comunidad científica reconoce el papel preponderante que tiene la Geoecología en la integración del conocimiento geográfico y ecológico desde una perspectiva territorial (Bocco, 2003; Konovalova and Plyusnin, 2018). Bajo este orden de ideas, la Geografía Física Compleja (GFC) constituye un enfoque geoecológico importante, ya que considera al paisaje como un sistema territorial compuesto por elementos naturales y antropogénicos condicionados socialmente, que modifican las propiedades de los paisajes naturales originales (Mateo, 1984, 2002); clasificando los mismos bajo los principios estructuro-genético e histórico-evolutivo.

En las últimas décadas, las investigaciones sobre heterogeneidad geoecológica realizadas bajo el enfoque de la GFC han permitido conocer a través de evaluaciones cuantitativas los niveles de geodiversidad que alberga un determinado territorio; estos estudios consideran las peculiaridades que poseen los paisajes en la estructura horizontal (Mateo, 1984; Fetisov, 2011; Ganzei and Ivanov, 2012; Semenov, 2014; Priego y Esteve, 2017).

Los resultados muestran en primera instancia que la GFC es una aproximación efectiva para explorar tópicos de biodiversidad y geodiversidad a nivel territorial; además, permite comprender la distribución de la biodiversidad a nivel de ecosistemas geográficos, la dinámica de los procesos y patrones ecológicos, así como la fragmentación ecológica de los territorios (Priego et al., 2013); por tanto, estas investigaciones son muy útiles, debido a que identifican espacios estratégicos destinados a la protección y conservación de la riqueza biótica y abiótica; además, esclarecen el grado de representatividad paisajista que posee un sistema de áreas protegidas (Ganzei and Ivanov, 2012; Lavrinenko, 2012); sirven de base óptima para la planificación territorial (Semenov, 2017) y como criterio válido para evaluar la sustentabilidad del desarrollo de un territorio (Klimina and Mirzekhanova, 2014).

En el marco de las estrategias para la conservación del planeta, México tiene un papel preponderante, debido a que es uno de los países con mayor biodiversidad en el mundo (Sarukhán et al., 2009). En este sentido, Palacio (2013) señala que en numerosos casos esta condición biológica es acompañada por una riqueza abiótica de tipo geólogo-geomorfológica. A pesar de ello, las investigaciones sobre heterogeneidad geoecológica en el país son escasas y espacialmente limitadas (Priego y Esteve, 2017); sin embargo, destacan los estudios realizados por Ramírez et al. (2016), Priego y Esteve (2017); la primera investigación abordó la temática bajo una visión regional, mientras que la segunda fue realizada a nivel nacional. 
La presente investigación se realizó en el estado de Chiapas, que es considerado por la Comisión Nacional para el Conocimiento y Uso de la Biodiversidad (2013) como la segunda entidad con mayor riqueza biológica en México. Ante esta situación, la entidad ha sido objeto de relevantes estudios biológicos y ecológicos (González et al.,2005; Villalobos, 2013); sin embargo, los estudios geoecológicos bajo una visión geomorfológica son escasos (Hernández et al., 2009); aunado a lo anterior, la falta de un desarrollo sustentable ha generado en las últimas décadas un uso inapropiado del territorio, esto ha derivado en una degradación acelerada de los recursos naturales y una pérdida de biodiversidad (Muñoz et al., 2004; Bellato et al., 2013; Villafuerte, 2013, 2015).

El objetivo del presente estudio es conocer los niveles de heterogeneidad geoecológica y la distribución de éstos en el estado de Chiapas, con base en el mapa de los paisajes físico-geográficos, elaborado por Morales et al. (2017). Los resultados permitieron distinguir las singularidades más destacadas de los paisajes, en este sentido, los paisajes de mayor complejidad y diversidad geoecológica poseen una génesis tectónico-kárstica, tectónico-acumulativa y tectónico-intrusiva.

\section{Materiales y métodos}

\section{1. Área de estudio}

El estado de Chiapas se localiza en el sureste de la República Mexicana y cuenta con un área de aproximadamente $73670 \mathrm{~km}^{2}$, lo que representa $3.8 \%$ de la superficie total del país; esta condición territorial lo ubica en el noveno sitio a nivel nacional, superando a naciones centroamericanas como: Belice, El Salvador y Costa Rica (Instituto Nacional de Estadística y Geografía, 2000). Al norte, colinda con el estado de Tabasco; al sur, con el Océano Pacífico; al oeste, con los estados de Oaxaca y Veracruz; y al este y sureste, con la República de Guatemala. Las coordenadas geográficas extremas son: $14^{\circ} 32^{\prime} 00^{\prime \prime}$ y $17^{\circ} 59^{\prime} 00^{\prime \prime}$ de latitud norte, y $90^{\circ} 22^{\prime} 00^{\prime \prime}$ y $94^{\circ} 14^{\prime} 00^{\prime \prime}$ de longitud oeste (Figura 1).

Figura 1. Ubicación de la zona de estudio

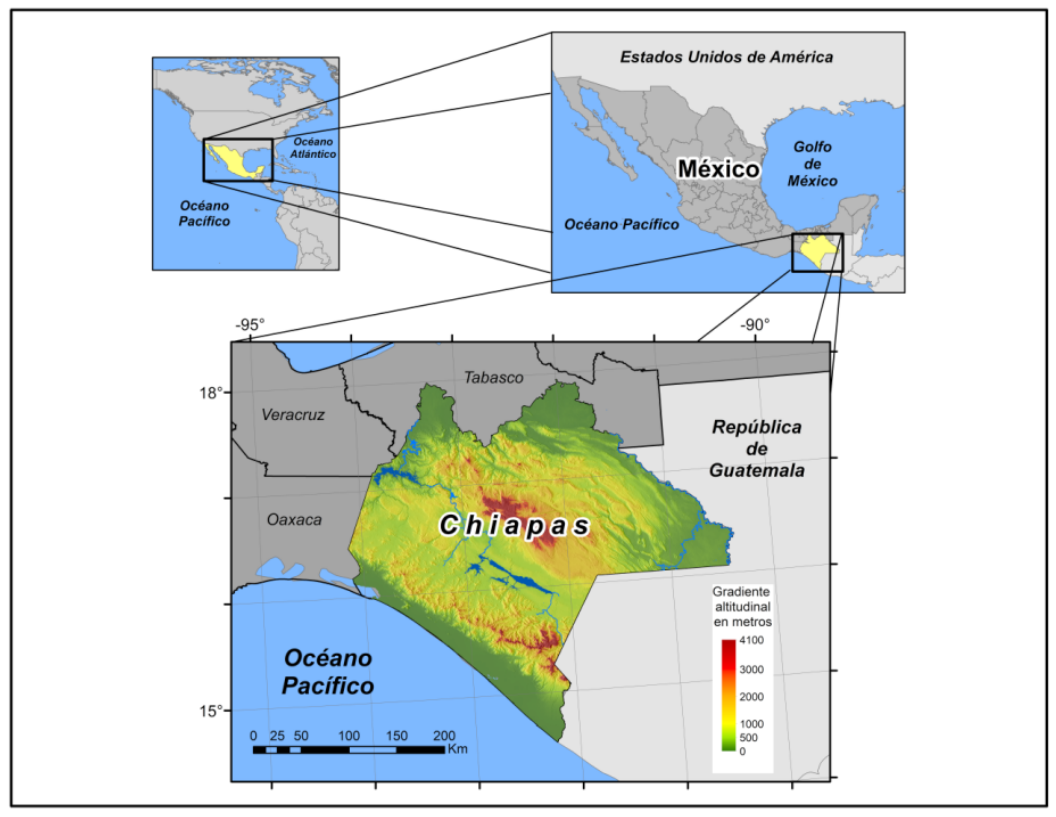

Fuente: Instituto Nacional de Estadística y Geografía (2000). Elaboración propia. 


\subsection{Los Paisajes físico-geográficos de Chiapas}

Según Morales et al. (2017:1) «Chiapas posee una elevada diversidad de paisajes con amplio predominio de los geocomplejos de génesis tectónico-kársticos y tectónico-intrusivo; aunque también están presentes geosistemas volcánicos, fluviales, lacustres y marino-terrígenos, entre otros». Esa investigación reconoció cartográficamente cinco niveles taxonómicos que incluyen: 6 clases, 19 subclases, 118 localidades, 181 parajes complejos y 450 parajes simples. En este sentido, el factor altitudinal se manifiesta como el principal elemento diferenciador de los paisajes físicogeográficos en el territorio chiapaneco; por tanto, la estructura vertical de los paisajes con mayor superficie considera un relieve de tipo montañoso bajo con dos tipos de génesis: tectónico-kárstico y tectónico-acumulativo en clima semicálido húmedo a subhúmedo.

\subsection{Marco teórico}

Desde principios del siglo XXI, la literatura internacional reconoce la existencia de dos grandes direcciones en la Ecología del Paisaje (Moss, 2001), la «bioecológica», que se distingue por un enfoque biocéntrico, representado por el modelo matriz-parche-corredor propuesto por la escuela norteamericana (Forman y Godron, 1986, Forman, 1995), y la dirección "geoecológica», que establece unidades integrales del espacio geográfico, esta aproximación incluye los enfoques ruso, alemán, francés, australiano, israelí y holandés, entre otros. Un detallado análisis de estas últimas escuelas geográficas se puede encontrar en el trabajo de Bocco et al. (2010).

La presente investigación se realizó bajo los principios teórico-metodológicos de la GFC. Esta aproximación geoecológica se distingue por analizar y clasificar los paisajes, bajo un punto de vista estructuro-genético e histórico-evolutivo, y considera al paisaje como sinónimo de geosistema, geocomplejo o complejo territorial natural (CTN), debido a que constituyen unidades de orden natural o antropo-natural, diferenciadas espacialmente por su origen y estructura (Isachenko, 1973; Mateo, 1984, 2002; Hasse, 1986; Frolova, 2006; Shaw y Olfield, 2007; Semenov y Snytko, 2013; Semenov, 2014). En este sentido, Mateo (1984, 2002, 2015), Mateo y Bollo (2016), señalan que los paisajes son sistemas territoriales integrados por componentes naturales y complejos de diferente rango taxonómico, formados bajo la influencia de los procesos naturales y de la actividad modificadora de la sociedad humana, que se encuentran en permanente interacción y se desarrollan históricamente.

Actualmente, las investigaciones sobre la heterogeneidad geoecológica se desarrollan bajo dos puntos de vista (Fetisov, 2011; Ganzei e Ivanov, 2012); el primero destaca por ser un tanto más geográfico, ya que considera los aspectos histórico-genéticos del paisaje mediante el componente geólogo-geomorfológico (enfoque geoecológico, según Moss, 2001); mientras que el segundo, pondera más las funciones de éste a través de los patrones espaciales, o sea, el enfoque bioecológico de la ecología del paisaje (Moss, 2001), basado en el modelo matriz-parches-corredor; generado por los tipos de vegetación y los usos de suelo; los cuales son obtenidos mediante la aplicación de técnicas de percepción remota y sistemas de información geográfica (Naveh, 1994; Frohn, 1998).

Bajo el primer enfoque, la heterogeneidad geoecológica de un territorio está dada por las peculiaridades presentes en la estructura horizontal (arreglo planar y morfológico) de un paisaje; es decir, por el número y el tamaño de polígonos, así como la cantidad de entidades tipológicas que integran a éste (Mateo, 1984). En este sentido, Priego et al. $(2003,2013)$ mencionan que la heterogeneidad del paisaje está condicionada por la composición en tipos y número de polígonos 
de cada clase con respecto a la unidad superior del paisaje. Para Hasse (1986), Fetisov (2011) y Priego et al. $(2004,2013)$, la estructura horizontal del paisaje es una de las características más importantes, ya que define las propiedades de complejidad y variabilidad de un sistema natural, en donde el componente geólogo-geomorfológico juega un papel preponderante, debido a que establece los limites espaciales de un paisaje y determinan dicha estructura (Lopatin and Zhirov, 2017).

Por su parte, el segundo enfoque representado por la Ecología del Paisaje (EP),que define a la heterogeneidad paisajista como la categoría o estado de consistencia de diferentes elementos, generado por los tipos de vegetación y uso de suelo; siendo así, un concepto opuesto a la homogeneidad (Forman, 1995; Turner et al., 2001). Para esta disciplina, la heterogeneidad del paisaje se expresa espacialmente a través de diferentes modelos espaciales: parche, corredor y matriz (Forman and Godron, 1986; Etter, 1991).

Bajo estas posturas, Ganzei e Ivanov (2012) sugieren el término «diversidad paisajista» para las investigaciones desarrolladas bajo el enfoque de la GFC; mientras que los estudios realizados por la EP podrían ser llamados «diversidad de ecosistemas».

\subsection{Estimación y representación cartográfica de la diversidad paisajista}

La presente investigación exploró la diversidad paisajista mediante la aplicación de cinco índices (Tabla 1): 1) Complejidad corológica, 2) Complejidad tipológica (Snacken y Antrop, 1983), 3) Riqueza relativa (Romme, 1982; Turner, 1989), 4) Diversidad máxima, 5) Diversidad de McIntosh (Turner, 1989; McIntosh, 1991).

Tabla 1. Índices para evaluar la heterogeneidad del paisaje

\begin{tabular}{|l|l|l|}
\hline Índice & Ecuación & Referencia \\
\hline Complejidad corológica $(\mathrm{CC})$ & $\mathrm{CC}=\mathrm{ni} / \mathrm{A}$ & Snacken y Antrop (1983) \\
\hline Complejidad tipológica $(\mathrm{CT})$ & $\mathrm{CT}=\mathrm{ni} / \mathrm{Nc}$ & Snacken y Antrop (1983) \\
\hline Riqueza relativa de los paisajes (R) & $\mathrm{R}=\mathrm{Nc} / \mathrm{Ncmax}$. & Romme (1982); Turner (1989) \\
\hline Diversidad máxima (Hmax) & $\mathrm{Hmax}=\ln (\mathrm{Nc})$ & Turner (1989) \\
\hline Diversidad de Mclntosh (U) & $\mathrm{U}=\sqrt{ } \Sigma \mathrm{ni2}$ & Mclntosh (1991) \\
\hline
\end{tabular}

Dónde: $\mathrm{n}_{\mathrm{i}}=$ número de entidades (polígonos) de la clase $i$ en la unidad; $\mathrm{Nc}=$ número de clases de paisajes presentes en la unidad; $\mathrm{Nc}_{\max }=$ número máximo de clases de paisajes posibles de ocurrir en la unidad; $\mathrm{A}=$ área de la unidad $\left(\mathrm{km}^{2}\right)$.

Fuente: Elaboración propia.

Estos indicadores son aplicados generalmente en el campo de la Ecología para conocer la biodiversidad tipo alfa (Turner y Gardner, 1991; Moreno, 2001). En este caso, se computó el número de polígonos y clases tipológicas contenidas, a nivel de paraje complejo y paraje simple (Aguirre, 2010), según el mapa elaborado por Morales et al. (2017), en donde la cantidad de polígonos equivale al número de individuos y las clases de paisajes es igual al número de especies.

Para simplificar la representación cartográfica de los resultados, se analizó el nivel de asociación; para ello, se aplicó una prueba de normalidad de datos mediante el test de Shapiro-Wilk; ante la falta de esta condición, se efectuó la prueba de coeficiente de correlación por rangos de Spearman. Este análisis se realizó en el programa Statistica ver. 10 (StatSoft, Inc., 2011). Posteriormente, los 
valores generados por cada indicador con excepción de $(\mathrm{R})$ fueron clasificados bajo el método de rompimientos naturales, debido a que dicha técnica estadística permite definir grupos de datos entre las clases (Environmental System Research Institute, 2012). Para el caso de (R), los datos fueron agrupados en clases iguales. Todos los resultados reconocen cinco categorías: a) Muy alto, b) Alto, c) Medio, d) Bajo, e) Muy bajo.

El análisis geográfico se desarrolló a escala 1: 250 000, mientras que la edición de los documentos cartográficos se realizó en una escala 1: 2400 000. Cabe señalar, que la regionalización físicogeográfica de México propuesta por Bollo et al. (2015) fue el marco espacial para analizar la distribución de la diversidad paisajista. Para cumplir con el trabajo cartográfico, se aplicaron diferentes módulos del sistema de información geográfica ArcGIS Desktop (Environmental System Research Institute, 2012).

\section{Resultados}

\subsection{Relación estadística y geográfica de los indicadores de complejidad y diversidad paisajista}

Los resultados estadísticos reconocen dos clases de correlación, la primera de ellas se distingue por ser negativa y poco significativa, mientras que la segunda es positiva y relevante. Bajo este escenario, la asociación de CC con el resto de indicadores genera correlaciones del primer tipo; en contraste, las relaciones entre $\mathrm{CT}, \mathrm{R}, \mathrm{U}$ y Hmax, producen asociaciones que responden al segundo modelo; esto obedece a las peculiaridades que poseen los paisajes en su estructura horizontal, así como al arreglo matemático que tiene cada parámetro. En este sentido, la ecuación de CC difiere del resto de indicadores, ya que además de contemplar la cantidad de polígonos albergados dentro de un determinado número de clases, considera la superficie ocupada por éstos. Por su parte, las ecuaciones de los indicadores CT, R, U y Hmax solo toman en cuenta las clases tipológicas alojadas en un orden taxonómico superior (Tabla 2).

Tabla 2. Matriz de correlación entre indicadores de heterogeneidad geoecológica

\begin{tabular}{|l|l|l|l|l|l|}
\hline $\begin{array}{l}\text { Indicadores } \\
\text { de heterogeneidad }\end{array}$ & CC & CT & $R$ & $U$ & Hmax \\
\hline CC & - & & & & \\
\hline CT & -0.16 & - & & & \\
\hline R & -0.14 & 0.51 & - & & \\
\hline U & -0.14 & 0.97 & 0.65 & - & \\
\hline Hmax & -0.14 & 0.51 & 1 & 0.65 & - \\
\hline
\end{tabular}

CT: Complejidad tipológica; CC: Complejidad corológica; R: Riqueza relativa de los paisajes; Hmax: Diversidad máxima; U: Diversidad de Mclntosh. Fuente: Elaboración propia.

Con base en lo anterior, la presente investigación destaca la presencia de tres correlaciones; la primera de ellas se establece entre la complejidad corológica y tipológica (CC-CT); la segunda se manifiesta entre la diversidad de McIntosh y la complejidad tipológica (U-CT); mientras que la tercera asocia la diversidad máxima (Hmax) con la riqueza relativa $(\mathrm{R})$. La primera asociación responde al primer tipo de correlación estadística, mientras que las dos restantes se identifican con el segundo. 
Para representar de manera simplificada la correspondencia espacial de los indicadores a través de cartogramas se generó un sistema matricial, en donde los resultados manifiestan la presencia de una amplia y dispersa asociación espacial entre CC y CT (Tabla 3). Esta situación obedece a dos condiciones geográficas: la extensión territorial y el número de polígonos o entidades albergados en un tipo de paisaje. En este sentido, las categorías baja y muy baja de CC se establecen en una considerable cantidad de parajes complejos con extensa superficie; en contraste, los niveles altos y muy altos se ubican en una minoría de parajes complejos, cuya condición territorial es limitada. La segunda condición influye en las categorías del parámetro CT, debido a que los niveles más altos se establecen en aquellos parajes complejos, que consideran un elevado número de polígonos en su interior; éstos corresponden a los paisajes de mayor extensión territorial o de menor CC. Bajo este escenario, se puede señalar que las condiciones estructurales de los paisajes genera una cierta contraposición entre ambos parámetros.

Tabla 3. Correspondencia espacial entre complejidad corológica y tipológica

\begin{tabular}{|c|c|c|c|c|c|c|c|c|c|c|c|c|c|c|c|c|c|}
\hline C-CT & \multicolumn{5}{|c|}{ MB } & \multicolumn{4}{|c|}{ B } & \multicolumn{3}{|c|}{$M$} & \multicolumn{3}{|c|}{ A } & \multicolumn{2}{|c|}{ MA } \\
\hline $\mathrm{C}-\mathrm{CC}$ & MB & B & $\mathrm{M}$ & A & MA & $\mathrm{MB}$ & $B$ & $\mathrm{M}$ & $A$ & $\mathrm{MB}$ & B & $\mathrm{M}$ & MB & B & $\mathrm{M}$ & MB & $M$ \\
\hline
\end{tabular}

C: Categoría; CC: complejidad corológica; CT: complejidad tipológica; MB: Muy baja; B: Baja; M: Media; A: Alta; MA: Muy Alta. Fuente: Elaboración propia.

Por su parte, la asociación entre U y CT se distingue por ser estrecha y concentrada, esto se traduce geográficamente en una alta correspondencia espacial, debido a que ambos indicadores consideran la misma variable, es decir, la cantidad de polígonos albergados en una clase superior (Tabla 4). En el caso de U, la ecuación calcula bajo un arreglo matemático cuadrado, la cantidad total de polígonos que integran un determinado tipo de paisaje; mientras que el indicador CT, estima la relación equitativa que establece el número de polígonos y las clases tipológicas.

Tabla 4. Correspondencia espacial entre diversidad de Mclntosh y complejidad tipológica

\begin{tabular}{|l|l|l|l|l|l|l|l|l|l|}
\hline C-CT & \multicolumn{2}{l|}{ MB } & \multicolumn{2}{l|}{ B } & \multicolumn{2}{l|}{ M } & A & MA \\
\hline C-U & MB & B & MB & B & M & M & A & A & MA \\
\hline
\end{tabular}

C: Categoría; U: diversidad de Mclntosh; CT: complejidad tipológica; MB: Muy baja; B: Baja; M: Media; A: Alta; MA: Muy Alta. Fuente: Elaboración propia.

Finalmente, la diversidad máxima $\left(\mathrm{H}_{\max }\right)$ y la riqueza relativa $(\mathrm{R})$ muestran una asociación perfecta; por tanto, una alta correspondencia espacial (Tabla 5). Esta relación es lógica, debido a que la ecuación de ambos indicadores considera la misma variable (número de clases tipológicas), aunque bajo un arreglo matemático distinto. En este sentido, el primer indicador estima de manera exponencial, la heterogeneidad contenida en un territorio, mientras que el segundo calcula la proporción entre el número de clases existentes con respecto a un máximo posible.

Tabla 5. Correspondencia espacial entre diversidad máxima y riqueza relativa

\begin{tabular}{|l|l|l|l|l|l|}
\hline C-R & MB & B & M & A & MA \\
\hline C-Hmax & MB & B & M & A & MA \\
\hline
\end{tabular}

C: Categoría; Hmax: diversidad máxima, R: riqueza relativa de los paisajes; MB: Muy baja; B: Baja; M: Media; A: Alta; MA: Muy Alta. Fuente: Elaboración propia. 


\subsection{Complejidad paisajista}

De acuerdo con la asociación de CC y CT, la mayoría de los parajes complejos adquieren las categorías muy baja, baja y media, mientras que una minoría manifiesta niveles altos y muy altos (Figura 2).

Figura 2. Niveles de complejidad por superficie ocupada

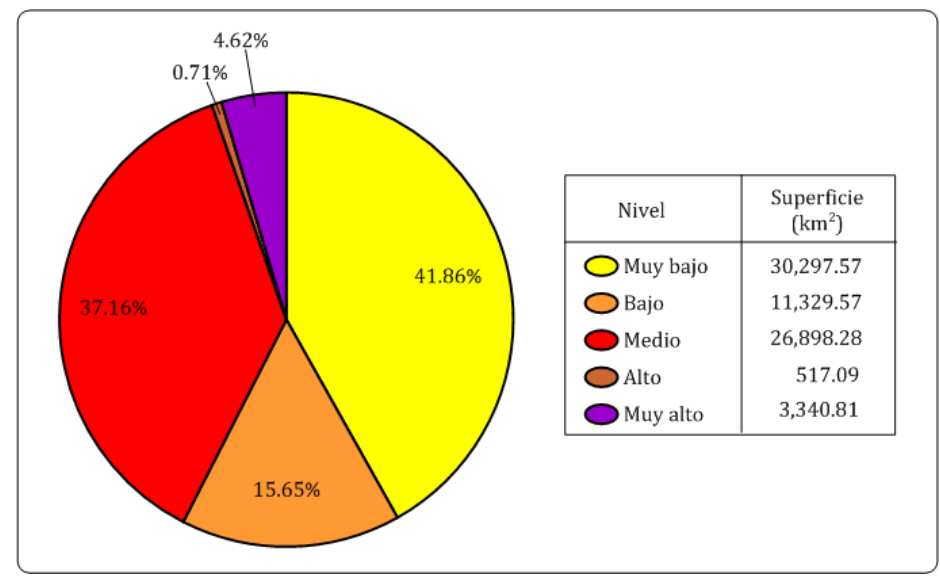

Fuente: Elaboración propia.

Bajo este panorama, los paisajes de categoría muy baja, se caracterizan por poseer valores bajos a muy bajos de CC y CT; por tanto, manifiestan una fuerte desproporción entre el número de entidades que integran la clase i (pocos polígonos dentro de un paraje simple de extensa superficie) y el número de clases que representan, es decir, escasos parajes simples (Tabla 6). Estos paisajes cubren más de $41 \%$ de la superficie del estado y se distribuyen en forma de amplios parches por los paisajes de planicies de origen tectónico y fluvial, en clima cálido húmedo y subhúmedo; así como en los paisajes montañosos de génesis volcánica, en clima frío, semifrío, templado y cálido húmedo, pertenecientes a las provincias físico-geográficas Llanura Costera Meridional del Golfo de México, Sierras Bajas del Peten, Depresión Central de Chiapas, Sierras del Sur de Chiapas, Volcanes de Centroamérica, Llanura del Istmo y Llanura Costera de Chiapas y Guatemala (Figura 3).

Por su parte, los paisajes de rango medio manifiestan un fuerte contraste en su estructura horizontal, debido a que poseen bajos a muy bajos niveles de CC y altos a muy altos de CT, esto significa la existencia de un escaso número de polígonos de una clase determinada de extensa superficie, así como una elevada cantidad de polígonos de una clase dada, albergados en pocas clases tipológicas (Tabla 6). Esta categoría abarca 37 \% de la superficie estatal y se distribuyen en forma de amplios corredores sobre paisajes montañosos de origen tectónico-acumulativo, tectónico-kárstico y tectónico-intrusivo, en clima semicálido húmedo a subhúmedo, cálido húmedo y cálido subhúmedo, ubicados en las provincias físico-geográficas Sierra Lacandona, Sierras del Norte y Sur de Chiapas (Figura 3).

Los paisajes de complejidad baja poseen valores medios de CC y bajos en CT, esto significa un cierto equilibrio entre el número de polígonos y las clases tipológicas albergadas en un paraje complejo de superficie relativamente extensa (Tabla 6). Esta categoría ocupa un área que representa $15 \%$ del territorio estatal, se distribuye en forma de tres grandes parches aislados en paisajes montañosos de origen tectónico-kárstico y tectónico-acumulativo, en climas templado típico, cálido húmedo y subhúmedo, en las regiones físico-geográficas Montañas de Los Altos de 
Chiapas, en partes de las Sierras del Norte de Chiapas, Sierra Lacandona, Sierras Bajas del Peten y Sierras del Sur de Chiapas (Figura 3).

Tabla 6. Niveles de complejidad

\begin{tabular}{|c|c|c|}
\hline \multicolumn{2}{|c|}{ Categorías asociadas (CC-CT) } & Propiedades \\
\hline \multicolumn{2}{|c|}{ Muy baja } & \multirow{2}{*}{$\begin{array}{l}\text { Baja a muy baja complejidad. Fuerte } \\
\text { desproporción relativa entre número } \\
\text { de polígonos (muy pocos) y área de } \\
\text { las unidades (muy extensas), así como } \\
\text { fuerte desigualdad entre el número de } \\
\text { polígonos (pocos) y de clases tipológi- } \\
\text { cas (pocas). }\end{array}$} \\
\hline$(0.00-0.24)$ & $(0.5-23.50)$ & \\
\hline \multicolumn{2}{|c|}{ Baja } & \multirow{2}{*}{$\begin{array}{l}\text { Media a muy baja complejidad. Cierta } \\
\text { desproporción relativa entre número de } \\
\text { polígonos (pocos) en áreas geográficas } \\
\text { (extensas), así como pocas clases tipo- } \\
\text { lógicas. }\end{array}$} \\
\hline$(0.00-0.39)$ & $(0.05-44.00)$ & \\
\hline \multicolumn{2}{|c|}{ Media } & \multirow{2}{*}{$\begin{array}{l}\text { Baja a muy baja complejidad corológica } \\
\text { y alta a muy alta complejidad tipológi- } \\
\text { ca. Fuerte desproporción relativa entre } \\
\text { número de polígonos (pocos) y área } \\
\text { de las unidades (extensas) o fuerte } \\
\text { desproporción relativa entre número de } \\
\text { polígonos (muchos) y clases tipológicas } \\
\text { (pocas). }\end{array}$} \\
\hline$(0.00-0.24)$ & $(44.00-126.67)$ & \\
\hline \multicolumn{2}{|c|}{ Alta } & \multirow{2}{*}{$\begin{array}{l}\text { Alta a muy alta complejidad corológica } \\
\text { y baja a muy baja complejidad tipológi- } \\
\text { ca. Fuerte desproporción entre número } \\
\text { de polígonos (muchos) y área de las } \\
\text { unidades (pequeña extensión), así } \\
\text { como un considerable equilibrio entre } \\
\text { número de polígonos y de clases tipo- } \\
\text { lógicas. }\end{array}$} \\
\hline$(0.39-4.79)$ & $(0.5-23.50)$ & \\
\hline \multicolumn{2}{|c|}{ Muy alta } & \multirow{2}{*}{$\begin{array}{l}\text { Media a Alta complejidad. Fuerte des- } \\
\text { proporción relativa entre número de } \\
\text { polígonos (muchos) y área de las uni- } \\
\text { dades (pequeña extensión), además } \\
\text { de una elevada desproporción entre } \\
\text { número de polígonos (muchos) y clases } \\
\text { tipológicas (pocas). }\end{array}$} \\
\hline$(0.24-0.39)$ & $(23.50-126.67)$ & \\
\hline
\end{tabular}

Fuente: Elaboración propia.

Por su parte, los paisajes de muy alta complejidad destacan por mantener los valores medios en CC y medios a muy altos en CT; esto representa espacialmente una fuerte desigualdad entre el número de polígonos (muchos) y las clases que representa (pocas) en un área reducida (Tabla 6). Los paisajes con estas peculiaridades abarcan un área que representa $4.62 \%$ del territorio chiapaneco, se distribuyen en forma de pequeños conglomerados aislados en geocomplejos de origen tectónico-kárstico, tectónico-acumulativo y tectónico-intrusivo, en clima semicálido húmedo a subhúmedo, cálido húmedo y subhúmedo, en las provincias físico-geográficas Sierra Lacandona, Sierras del Norte de Chiapas y Depresión Central de Chiapas (Figura 3). 
Por último, los paisajes de alta complejidad muestran valores altos a muy altos en CC y bajos a muy bajos en CT, esto significa la presencia de una elevada cantidad de polígonos en parajes simples de superficie limitada y un cierto equilibrio entre el número polígonos de clase i y la cantidad de parajes simples (Tabla 6). Esta categoría representa tan solo $0.71 \%$ de la extensión territorial del estado, se distribuye en forma de pequeños conglomerados aislados, en paisajes cuyas condiciones genéticas son iguales a los mencionados en la categoría anterior, dentro de las provincias físico-geográficas Sierras del Norte y Sur de Chiapas principalmente (Figura 3).

Figura 3. Distribución de la complejidad (CC-CT) paisajista en Chiapas

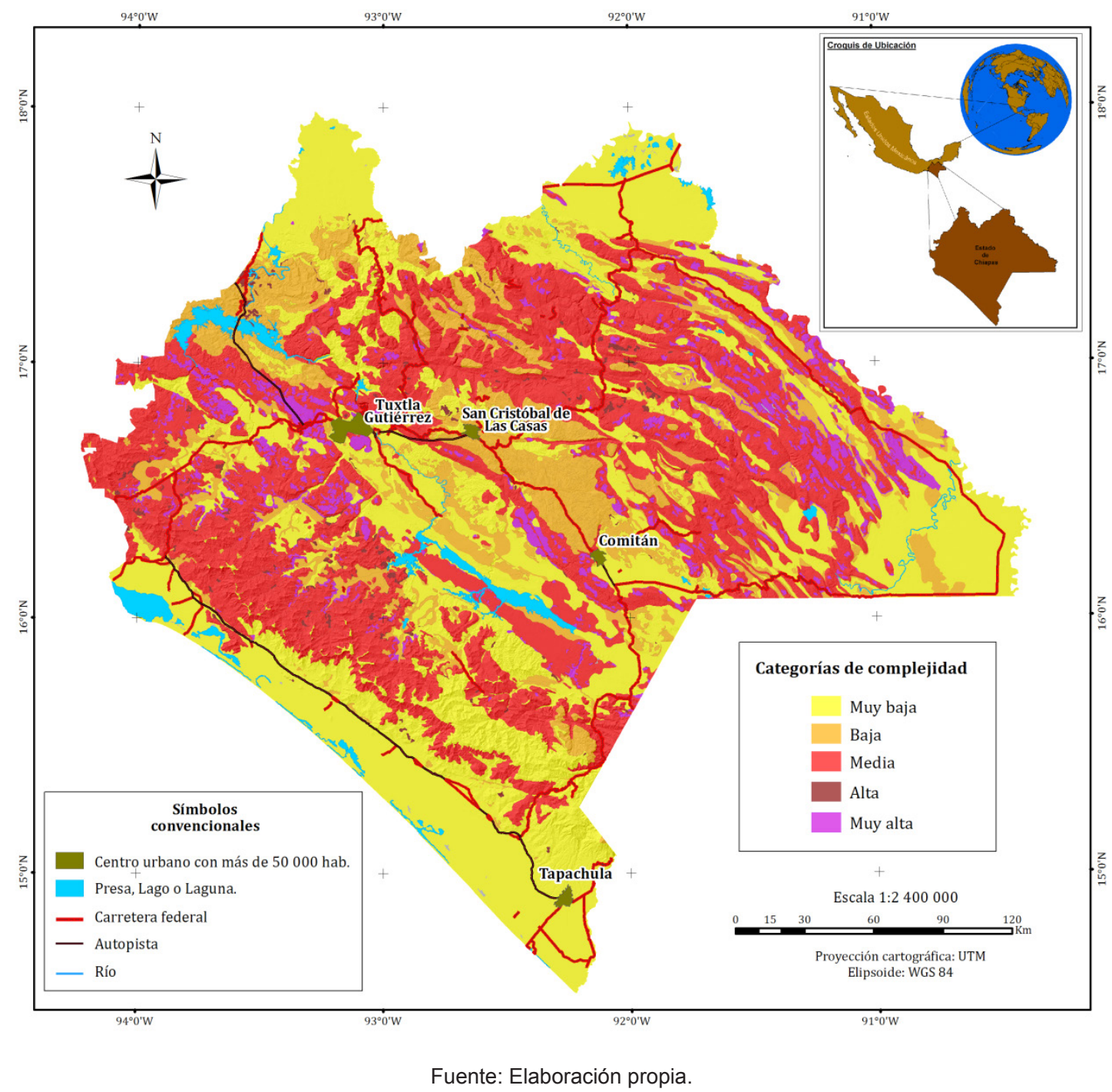

\subsection{Diversidad - Complejidad de los paisajes}

Las categorías generadas por la asociación entre U y CT manifiestan una distribución geográfica equitativa; en donde los paisajes de categorías alta y muy alta cubren casi $45 \%$ del área estatal; mientras que los paisajes de niveles bajo y muy bajo ocupan poco más de $35 \%$; finalmente, los geosistemas de rango medio abarcan 19\% (Figura 4). 
Los paisajes de categoría alta manifiestan elevados valores en $\mathrm{U}$, así como medios y altos en CT. Esta situación obedece a la presencia de un alto número polígonos por clase (paraje simple), que se encuentran albergados en escasas unidades superiores (parajes complejos) de extensa superficie (Tabla 7). Esta categoría abarca $27 \%$ del territorio estatal y se distribuye en forma de corredores en paisajes montañosos de origen tectónico-kárstico, tectónico-acumulativo y tectónicointrusivo, en clima templado, semicálido húmedo a subhúmedo, cálido húmedo y subhúmedo, ubicados en las provincias físico-geográficas Sierras del Norte y Sur de Chiapas, Montañas de Los Altos de Chiapas y en partes de la Sierra Lacandona (Figura 5).

Figura 4. Niveles de diversidad-complejidad paisajista por superficie ocupada

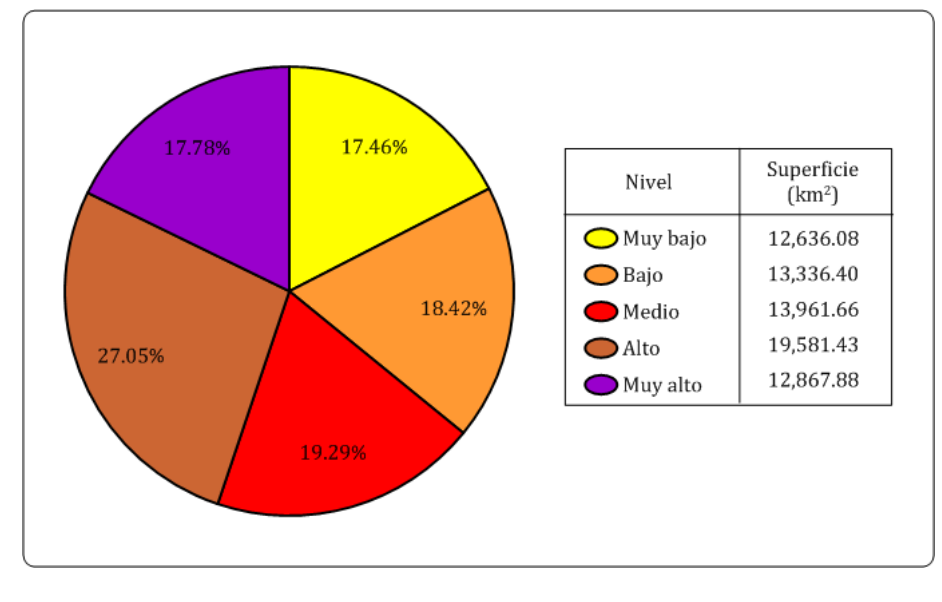

Fuente: Elaboración propia.

Respecto a los paisajes de categoría media, el indicador U se mantiene en el mismo nivel, mientras que el parámetro CT manifiesta un rango que va de medio a bajo. Esto representa espacialmente una cantidad moderada y equitativa de polígonos y parajes simples (Tabla 7). Esta categoría ocupa un poco más de 19\% del área estatal, se distribuyen en forma de parches aislados por todo el territorio, principalmente en paisajes montañosos tectónico-acumulativo y planicies tectónicas, ambos en climas cálido húmedo y subhúmedo, pertenecientes a las provincias físico-geográficas Sierras del Norte de Chiapas, Sierras Bajas del Peten, en partes de la Sierra Lacandona, Depresión Central de Chiapas y Volcanes de Centroamérica (Figura 5).

Por su parte, los paisajes de baja categoría manifiestan un bajo valor en $U$, en tanto que el indicador CT manifiesta niveles bajos y muy bajos, esto obedece a una baja cantidad de polígonos y clases tipológicas (Tabla 7). Esta categoría abarca un área que representa más de $18 \%$ con respecto al total de la extensión territorial del estado, se distribuye en forma de parches aislados por todo el territorio, principalmente en paisajes de montaña de origen tectónico-kárstico y planicie fluvial, en climas cálido húmedo y subhúmedo, pertenecientes a las provincias físico-geográficas Llanura Costera Meridional del Golfo, Sierras Bajas del Peten, partes de la Sierra Lacandona, Depresión Central de Chiapas y en las partes bajas de las Sierras del Sur de Chiapas (Figura 5).

Con respecto a los paisajes de categoría muy alta, destaca la presencia de altos valores en $\mathrm{U}$ y CT, esta situación genera espacialmente la presencia de un alto número de polígonos por clases en pocas unidades superiores (Tabla 7). La presente categoría ocupa casi $18 \%$ del área estatal, y se distribuye a manera de corredores por las partes Oriente, Centro y Centro-Norte del estado, principalmente en paisajes montañosos de génesis tectónico-kárstico y tectónico-acumulativo, en climas semicálido húmedo a subhúmedo y cálido húmedo, estos se ubican en las provincias 
físico-geográficas Sierra Lacandona, partes de las Sierras Norte de Chiapas, así como en el margen norte de la Depresión Central de Chiapas (Figura 5).

Por último, los paisajes de categoría muy baja, se caracterizan por mantener valores muy bajos en ambos parámetros, esto significa espacialmente la escasa presencia de polígonos por clase dentro de pocas unidades superiores (Tabla 7). Esta categoría abarca $17 \%$ del territorio chiapaneco y se distribuye en forma de parches aislados, principalmente en paisajes de planicie o llanura de origen tectónico-acumulativo, tectónico-intrusivo y fluvial, en climas cálido húmedo y subhúmedo, ubicados en las provincias físico-geográficas Llanura Costera Meridional del Golfo, Sierras Bajas del Peten, Sierra Lacandona y partes de la Depresión Central de Chiapas. Cabe señalar, que en la parte Sur y Sureste del estado, la presente categoría presenta un patrón espacial en forma de corredor (Figura 5).

Figura 5. Distribución de la diversidad - complejidad paisajista en Chiapas

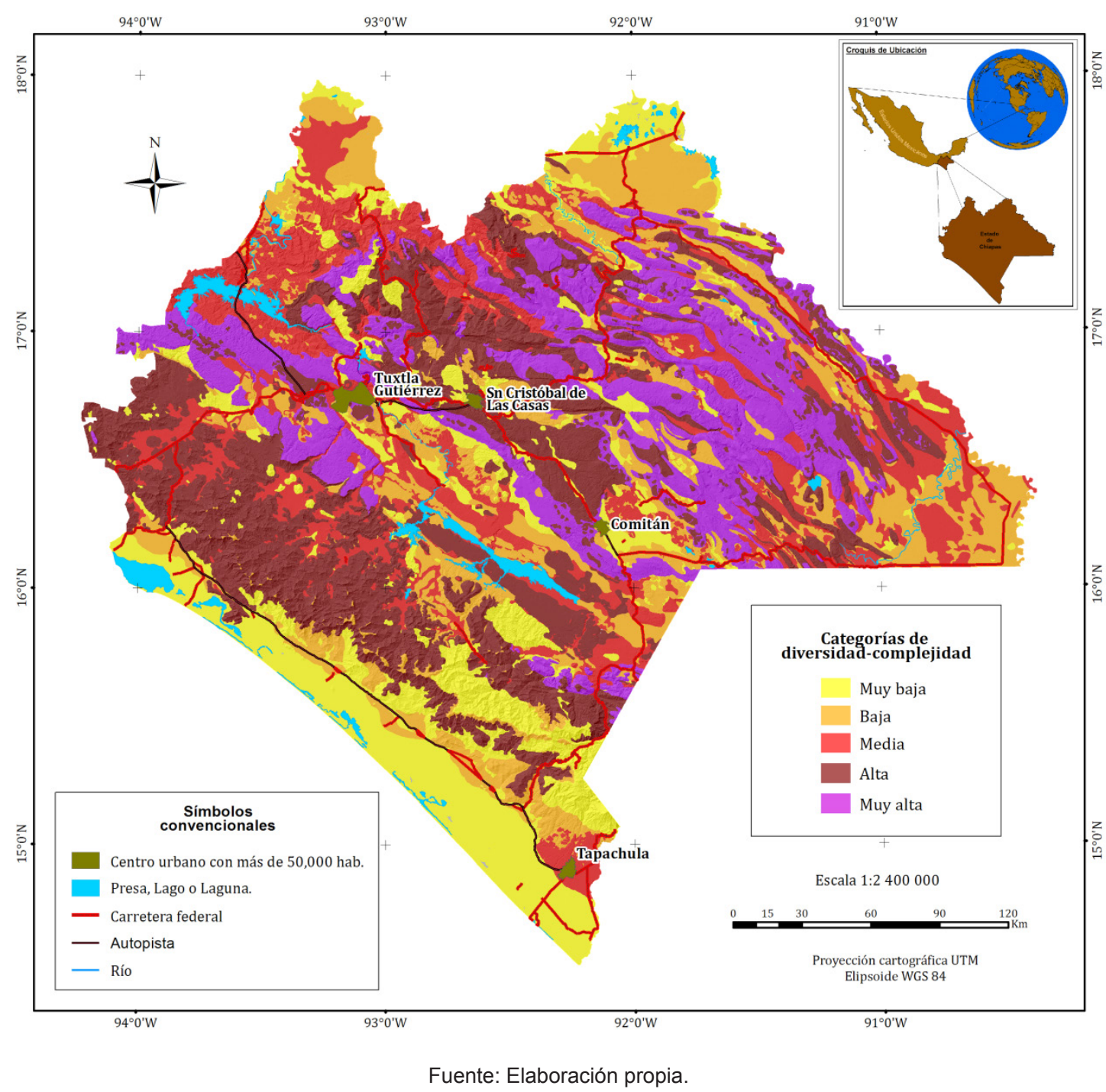


Tabla 7. Niveles de diversidad - complejidad

\begin{tabular}{|c|c|c|}
\hline \multicolumn{2}{|c|}{$\begin{array}{l}\text { Categorías asociadas } \\
\qquad(\mathrm{U}-\mathrm{CT})\end{array}$} & Propiedades \\
\hline \multicolumn{2}{|c|}{ Muy baja } & \multirow{2}{*}{$\begin{array}{l}\text { Muy baja diversidad y muy baja a baja } \\
\text { complejidad tipológica. Proporción rela- } \\
\text { tivamente equitativa entre el número de } \\
\text { polígonos (muy pocos) y de clases tipo- } \\
\text { lógicas (pocas). }\end{array}$} \\
\hline $1.0-16.49$ & $0.5-23.50$ & \\
\hline \multicolumn{2}{|c|}{ Baja } & \multirow{2}{*}{$\begin{array}{l}\text { Baja diversidad de Mclntosh y muy baja } \\
\text { a baja complejidad tipológica. Cierta des- } \\
\text { proporción relativa entre número de polí- } \\
\text { gonos (pocos) y pocas clases tipológicas. }\end{array}$} \\
\hline $16.49-35.44$ & $0.5-23.50$ & \\
\hline \multicolumn{2}{|c|}{ Media } & \multirow{2}{*}{$\begin{array}{l}\text { Moderada diversidad de McIntosh y una } \\
\text { complejidad tipológica baja a media. Una } \\
\text { proporción equitativa entre entidades de } \\
\text { la clase i en la unidad y el número de } \\
\text { clases paisajes presentes en la unidad } \\
\text { superior de paisaje. }\end{array}$} \\
\hline $35.44-67.11$ & $11.33-44.00$ & \\
\hline \multicolumn{2}{|c|}{ Alta } & \multirow{2}{*}{$\begin{array}{l}\text { Alta diversidad de Mclntosh y media a } \\
\text { alta complejidad tipológica. Alto número } \\
\text { de polígonos de la clase i en la unidad, } \\
\text { así como una fuerte desproporción entre } \\
\text { número de la clase i en la unidad y el } \\
\text { número de clases paisajes presentes en } \\
\text { la unidad. }\end{array}$} \\
\hline $67.11-150.25$ & $44.00-69.33$ & \\
\hline \multicolumn{2}{|c|}{ Muy alta } & \multirow{2}{*}{$\begin{array}{l}\text { Muy alta diversidad de Mclntosh y muy } \\
\text { alta complejidad tipológica. Fuerte des- } \\
\text { proporción relativa entre número de polí- } \\
\text { gonos (muchos) y las clases tipológicas } \\
\text { (pocas). }\end{array}$} \\
\hline $150.25-244.9$ & 69.33-126.67 & \\
\hline
\end{tabular}

Fuente: Elaboración propia.

\subsection{Diversidad-Riqueza de los paisajes}

Bajo la asociación Hmax-R, la categoría media ejerce un predominio territorial, ya que se establece en la mayoría de los paisajes de montaña (los más extensos). Esta situación contrasta con la baja representatividad espacial que tienen los demás niveles ubicados en paisajes de menor superficie, cuya composición geomorfológica está dada por llanuras (Figura 6). Bajo este escenario, los paisajes de categoría media se distinguen estructuralmente por manifestar un cierto equilibrio entre los valores de Hmax y R, debido a que ambas están integradas por tres clases tipológicas (Tabla 8). Esta categoría se distribuye principalmente por los paisajes montañosos que integran las provincias físico-geográficas Sierras del Norte de Chiapas, Sierras del Sur de Chiapas, Sierra Lacandona, Depresión Central de Chiapas, Volcanes de Centroamérica y partes de la Sierras Bajas del Peten (Figura 7). 
Figura 6. Grados de diversidad-riqueza paisajista por superficie ocupada

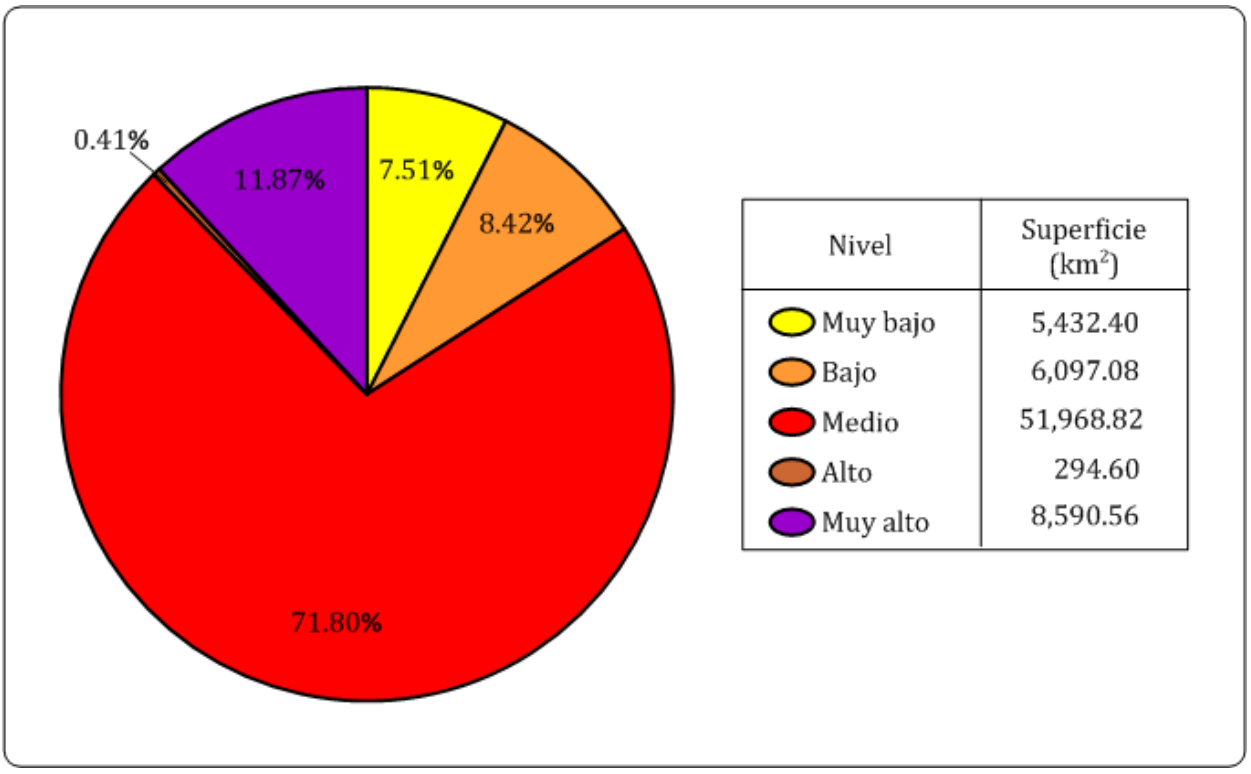

Fuente: Elaboración propia.

Figura 7. Distribución de la Diversidad - Riqueza paisajista de Chiapas

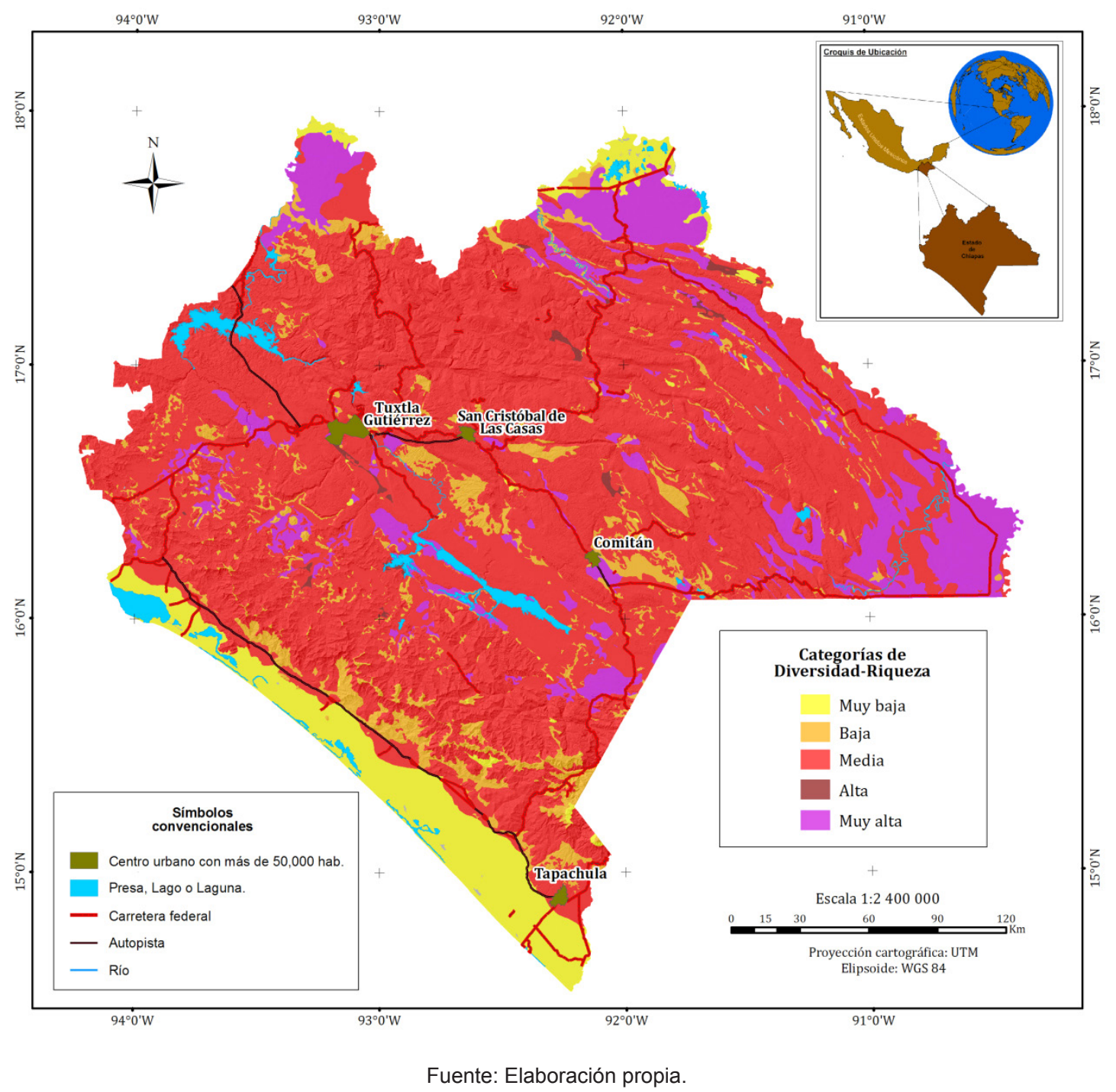


Por su parte, la categoría muy alta está conformada por un máximo de cinco clases tipológicas (Tabla 8). Este nivel ocupa poco más de $11 \%$ del territorio chiapaneco, se distribuye en forma de parches aislados sobre paisajes de llanuras de origen tectónico, en clima semicálido húmedo a subhúmedo, así como en cálido húmedo y subhúmedo. Estos paisajes conforman las provincias físico-geográficas Llanura Costera Meridional del Golfo, Sierras Bajas del Peten, Sierra Lacandona, Depresión Central de Chiapas y Sierras del Sur de Chiapas (Figura 7).

Tabla 8. Niveles de diversidad-riqueza

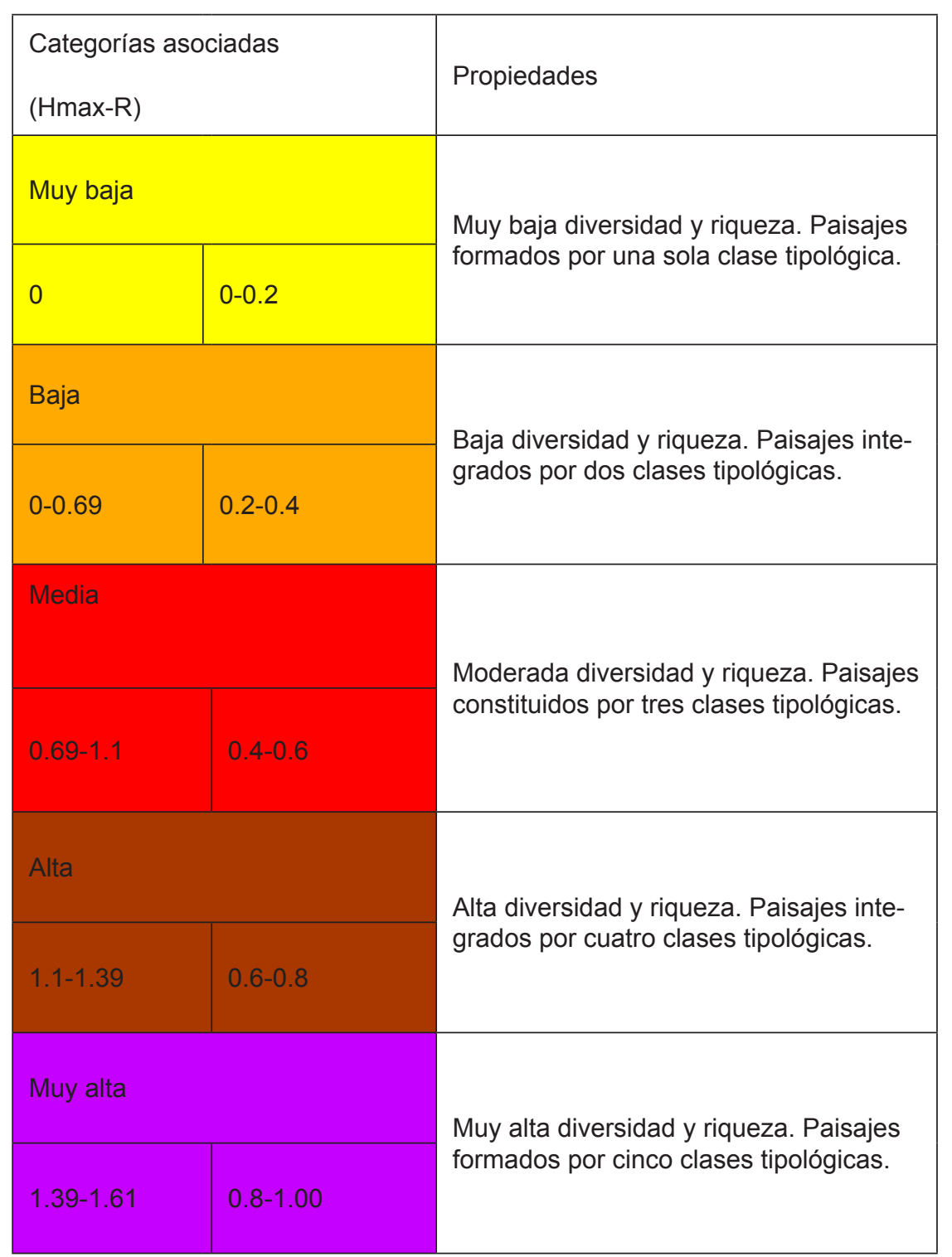

Fuente: Elaboración propia.

La categoría baja se establece en paisajes que poseen una estructura horizontal de dos clases tipológicas (Tabla 8). Este nivel abarca poco más de $8 \%$ de la superficie estatal, y se distribuye a manera de pequeños parches aislados en una minoría de paisajes montañosos de origen tectónicointrusivo, volcánico, y tectónico-kárstico, en climas frío de montaña, templado, semicálido húmedo a subhúmedo y cálidos húmedos, pertenecientes a las provincias físico-geográficas Sierra Lacandona, Sierras del Norte de Chiapas, Sierras del Sur de Chiapas, Volcanes de Centroamérica y Depresión Central de Chiapas (Figura 7). 
La categoría muy baja se manifiesta en paisajes cuya estructura horizontal está conformada por una clase tipológica (Tabla 8). Desde una perspectiva geográfica, este nivel considera menos de $8 \%$ del área estatal, y se distribuye en forma de parche aislado y corredor amplio, en paisajes de llanuras de origen tectónico, fluvial y palustre, en clima cálido húmedo y subhúmedo, pertenecientes a las provincias físico-geográficas Llanura Costera de Chiapas y Llanura Costera Meridional del Golfo (Figura 7).

Finalmente, la categoría alta se establece en los paisajes que poseen cuatro clases tipológicas (Tabla 8). Bajo una perspectiva geográfica, estos paisajes se distinguen por ocupar apenas $1 \%$ del territorio estatal; por tanto, su distribución se restringe a pequeños parches aislados ubicados en las provincias físico-geográficas Sierra Lacandona, Sierras del Norte de Chiapas y Sierras del Sur de Chiapas. La composición geomorfológica de estos paisajes está dada por llanuras de origen tectónico, en clima semicálido húmedo a subhúmedo y cálido húmedo (Figura 7).

\section{Discusión}

Los resultados de la presente investigación deben ser interpretados de manera cuidadosa y objetiva, debido a que el cálculo y el arreglo espacial que muestran las categorías de complejidad y heterogeneidad paisajista obedecen a una escala límite entre estudios de tipo regional y local (1:250 000).

En el marco de esta reflexión y de acuerdo con los resultados, es posible considerar que los niveles de geodiversidad que ostentan los paisajes son producto de procesos histórico-evolutivos, generados por los fenómenos tectónicos y volcánicos (factores diferenciadores del paisaje) acotados a un tiempo (edad del paisaje).

Bajo este argumento, se reconoce la relación directa que establecen los procesos genéticos del paisaje con los niveles de geodiversidad. En este sentido, los altos grados de geodiversidad presentes en los paisajes montañosos de origen tectónico, contrastan con los bajos niveles establecidos en los paisajes de montañas volcánicas; esta situación es más evidente al comparar los primeros con los paisajes de llanuras.

Otro factor esencial en la definición de categorías es la edad de los paisajes; bajo esta consideración, es posible señalar que los paisajes más antiguos representados por las génesis tectónicokárstico, tectónico-acumulativo y tectónico-intrusivo, presentan niveles altos de geodiversidad; en cambio, los paisajes más jóvenes de origen volcánico, fluvial, palustre y lacustre, manifiestan valores más bajos.

Con base en lo anterior, es posible considerar que los niveles más bajos de geodiversidad se concentran en una mayoría de paisajes, que poseen una estructura horizontal simple y relativamente homogénea; mientras que los niveles más altos se establecen en una minoría de paisajes, que se distinguen por ser los más repetibles y representativos; esta condición les confiere el nombramiento de paisajes típicos chiapanecos (geosistemas montañosos de origen tectónico-kárstico, tectónico-acumulativo y tectónico-intrusivo).

El modelo de mayor interés debido a su connotación ecológica, es generado por la asociación CT-U; en donde, los niveles más altos de complejidad-diversidad se distribuyen en forma de corredores sobre las mesoestructuras del relieve montañoso. Esta situación mantiene una corres- 
pondencia con la distribución de dos comunidades vegetales de mayor biodiversidad: el bosque mesófilo de montaña y la selva alta perennifolia (Pérez y Gómez, 2010; Villaseñor, 2010); por ende, este patrón paisajista identifica los ecosistemas más frágiles y de mayor potencial para la generación de servicios ambientales.

Por otra parte, el predominio espacial que establece el nivel medio de la asociación diversidadriqueza relativa (paisajes de estructura simple) y la preponderancia que tienen las categorías alta y muy alta de la correlación complejidad-diversidad (los paisajes más repetibles y representativos), permite inferir la posibilidad de un pasado histórico constituido por procesos geotectónicos relativamente homogéneos y continuos. Bajo esta consideración y de acuerdo con los resultados expuestos por Ramírez et al. (2016), se puede señalar que los procesos histórico-evolutivos han establecido diferencias notables entre los paisajes montañosos mexicanos.

Los paisajes de Alta y Muy Alta riqueza y diversidad abarcan más de $8880 \mathrm{~km}^{2}$, esta superficie asciende hasta más de $32400 \mathrm{~km}^{2}$, si se consideran los paisajes de Alta y Muy Alta diversidad y complejidad geoecológica (Figura 4 y 6 ).

La alta correlación espacial y estadística entre biodiversidad y geodiversidad (Priego et al., 2013), sugiere una mejora en el diseño espacial de las Áreas Naturales Protegidas en Chiapas; para ello, sería conveniente realizar una evaluación de la heterogeneidad geoecológica, teniendo como base una cartografía de los paisajes físico-geográficos a escalas más detallas (1:50 000, por ejemplo).

Por otro lado, en esta investigación solo hemos empleado cinco indicadores de heterogeneidad, sin embargo, sería conveniente explorar la dominancia, abundancia, y singularidad de los geosistemas. Estas sugerencias generan nuevas preguntas de investigación, que deben ser atendidas en el futuro cercano, dada la importancia ambiental que tiene Chiapas en el contexto nacional y mundial.

Finalmente, los resultados de la presente investigación confirman los resultados de complejidad y diversidad-riqueza obtenidos a nivel nacional por Priego y Esteve (2017); por tanto, esta situación le confiere una mayor solidez a los estudios sobre heterogeneidad paisajística en México.

\section{Conclusiones}

El uso de indicadores geoecológicos, bajo el enfoque de la Geografía Física Compleja, permitió esclarecer las peculiaridades más sobresalientes de la heterogeneidad paisajista en el estado de Chiapas. En este sentido, una correlación baja y negativa establecida por la complejidad, indica el predominio territorial de las categorías media, baja y muy baja; mientras que una asociación significativa y positiva, generada por la relación complejidad-diversidad identifica los paisajes más repetibles y representativos de la entidad (paisajes típicos). Por su parte, la asociación riquezadiversidad bajo un comportamiento estadístico similar a la anterior agrupación de indicadores, manifiesta una hegemonía territorial ejercida por la categoría media sobre los paisajes montañosos.

Por lo anterior, se reconoce la relación directa que establecen los componentes diferenciadores del paisaje (geólogo-geomorfológico y climático) con los factores de tipo biótico y socio-económico. En este sentido, los geosistemas con elevados niveles de geodiversidad (paisajes montañosos de origen tectónico-kárstico, tectónico-acumulativo y tectónico-intrusivo, en climas semicálido 
húmedo a subhúmedo, cálido húmedo y cálido subhúmedo) poseen una elevada connotación ecológica, debido a que constituyen el hábitat de comunidades vegetales con altos niveles de biodiversidad; además, las pulsaciones tectónicas del paisaje establecen patrones de distribución que rigen la conectividad de los distintos tipos de vegetación. Estos paisajes se ubican principalmente en las regiones físico-geográficas Sierra Lacandona, Montañas del Norte de Chiapas y Sierras del Sur de Chiapas.

Los paisajes de ambiente deposicional (paisajes de planicie tectónica y fluvial, en clima cálido húmedo y subhúmedo) tienen bajos niveles de geodiversidad, y una mayor asimilación económica; estos paisajes se ubican en las regiones Llanura Costera Meridional del Golfo, Llanura Costera de Chiapas y Depresión Central de Chiapas.

De acuerdo con lo anterior, se reconoce el papel significativo que han tenido los procesos tectónicos en la determinación de niveles y patrones de distribución de la geodiversidad; en donde, la zonalidad altitudinal se constituye como el principal factor de diferenciación paisajista en Chiapas. En este sentido, la asociación diversidad-riqueza permite reconocer el predominio de esfuerzos tectónicos relativamente homogéneos y constantes; que han generado un hábitat estable para diversas comunidades vegetales; por tanto, las condiciones tectónicas que poseen los paisajes chiapanecos los hace únicos en la República Mexicana.

Los resultados cartográficos obtenidos por la presente investigación constituyen un apoyo para las futuras investigaciones botánicas, ya que los altos niveles de geodiversidad se asocian con zonas de alta riqueza biológica o hot spot (Priego et al., 2004, 2013); además, identifican probables zonas de endemismo.

Finalmente, los resultados permiten generar nuevas preguntas; sin embargo, para poder responder éstas es necesario realizar estudios en aquellas regiones, que concentran los paisajes de alta diversidad y complejidad. Estos nuevos esfuerzos científicos deben de incluir inventarios de paisajes a escala más detallada, nuevos indicadores, así como el uso de mejores herramientas para el análisis espacial.

\section{Bibliografía}

- Aguirre, R. (2010). Unidades Campesinas de Paisajes. Estudio de Caso en el Ejido Nexpa, Michoacán (Tesis de maestría). Universidad Nacional Autónoma de México, Morelia.

- Bellato, L., Tinoco, R., Grajales, O. (2013). Pobreza y medio ambiente. En Comisión Nacional para el Conocimiento y Uso de la Biodiversidad y Gobierno del Estado de Chiapas (Eds.), La biodiversidad en Chiapas: Estudio de Estado (pp. 71-82). D.F., México: Editorial Impresora Apolo

- Bocco, G. (2003). Carl Troll y la ecología del paisaje. Gaceta Ecológica, (68), 69-70.

- Bocco, G., Mendoza, M., Priego, A., y Burgos, A. (2010). La cartografía de sistemas naturales como base geográfica para la planeación territorial. D.F., México: Secretaría del Medio Ambiente y Recursos Naturales-Instituto Nacional de Ecología-Centro de Investigaciones en Geografía Ambiental UNAM.

- Bollo, M., Hernández, J., Priego, A., Zaragoza, R., Ortiz, A., Espinoza, A., Ruíz, R. (2015). Una Propuesta de Regionalización Físico-Geográfica de México. Morelia, México: UNAM-CIGA.

- Comisión Nacional para el Conocimiento y Uso de la Biodiversidad (2013). La biodiversidad en Chiapas: Estudio de Estado. D.F., México: Comisión Nacional para el Conocimiento y Uso de la Biodiversidad-Gobierno del Estado de Chiapas.

- Environmental System Research Institute. (2012). Arc GIS Desktop ver.10.1. Redland California, United States of America: ESRI. 
- Etter, A. (1991). Introducción a la Ecología del Paisaje: Un Marco de Integración para los Levantamientos Rurales. Bogotá, Colombia: Instituto Geográfico Agustín Codazzi.

- Fetisov, D. (2011). Landscape Diversity in the Russian Part of the Lesser Khingam. Geography and Natural Resources, 32 (1), 116-121. doi: 10.1134/S1875372811010100

- Forman, R., Godron, M. (1986). Landscape Ecology. New York, United States of America: Wiley and Sons.

- Forman, R. (1995). Land Mosaics. Cambridge: Cambridge University Press.

- Frohn, R. (1998). Remote Sensing for Landscape Ecology. New Metric for Monitoring, Modeling, and Assessment of Ecosystems. Boca Raton, United States of America: Lewis Publishers.

- Frolova, M. (2006). Desde el concepto de paisaje a la Teoría de geosistema en la Geografía rusa: ¿hacia una aproximación geográfica global del medio ambiente?. Ería, (70), 225-235.

- Ganzei, K., Ivanov, A. (2012). Landscape Diversity of the Kuril Islands. Geography and Natural Resources, 33 (2), 87-94. doi: 10.1134/S1875372812020072

- González, M., Ramírez, N., Méndez, G., Galindo, L. Golicher, D. (2005). Riqueza de especies de árboles: variación espacial y dimensiones ambientales asociadas a nivel regional. En M. González, N. Ramírez, L. Ruíz (Coord.), Diversidad Biológica en Chiapas. México (pp. 81-125). D.F., México: Plaza y Valdés Editores.

- Hasse, G. (1986). Theoretical and methodological foundations of landscape ecology. En: International Training Course Landscape ecology. Abstract of Lecture (pp. 4 - 7) Leipzig, German Democratic Republic: Academy of Science of the German Democratic Republic Institute of Geography and Geoecology.

- Hernández, J., Bollo, M., Méndez, P., Figueroa, J. (2009). Formación y morfogénesis de relieve del extremo noroccidental del estado de Chiapas, México. Investigaciones Geográficas, (68), 25-40.

- Instituto Nacional de Estadística y Geografía. (2000). Marco Geoestadístico, 2000: Superficie de la República Mexicana por estados. Aguascalientes, México: Instituto Nacional de Estadística y Geografía.

- Isachenko, A. (1973). Principles of Landscape Science and Physical - Geographic Regionalization. Melbourne, Australia: Edit. J.S. Massey.

- Klimina, E., Mirzekhanova, Z. (2014): Developing the system of regional indices of landscape diversity for poorly developed territories. Geography and Natural Resources, 35 (1), 88-93. doi: 10.1134/S1875372814010132

- Konovalova, T., and Plyusnin, V. (2018). Development of the Geosystem Mapping Methodology. Geography and Natural Resources, 39 (3), 197 - 203. doi: 10.1134/S1875372818030022

- Kozlowski, S. (2004). Geodiversity. The concept and scope of geodiversity. Przeglad Geologiczny, (52), 833 - 837.

- Lavrinenko, I. (2012). Landscape Diversity of Spacially Protected Natural Territories of Nenets Autonomous Okrug. Geography and Natural Resources, 33 (1), 43 - 51. doi: 10.1134/S1875372812010064

- Lopatin, D., and Zhirov, A. (2017). Morphological systematics of the relief and its implications for geography and geoecology. Geography and Natural Resources, 38 (1), 30 - 37. doi: 10.1134/S1875372817010048

- Mateo, J. (1984). Apuntes de Geografía de los Paisajes. Ciudad de la Habana, Cuba: Editorial André Voisin, Empresa Nacional de Producción y Servicios del Ministerio de Educación Superior de Cuba.

- Mateo, J. (2002). Geoecología de los Paisajes: Bases para la Planificación y Gestión Ambiental. Ciudad de la Habana, Cuba: Ministerio de Educación Superior.

- Mateo, J. (2015). Teoría y Metodología de la Geografía. Ciudad de la Habana, Cuba: Editorial Universitaria Félix Varela.

- Mateo, J., Bollo, M. (2016). La región como categoría geográfica. Morelia, México: UNAM: CIGA.

- McIntosh, R. (1991). Concept and terminology of homogeneity and heterogeneity in ecology. En J. Kolasa and P. Steward (Coord.), Ecological Heterogeneity (pp. 24-26). New York, United State of America: Springer-Verlag.

- Morales, H., Priego, A., Bollo, M. (2017). Los paisajes físico-geográficos del estado de Chiapas, México a escala 1: 250 000. Terra Digitalis international e-journal of map, 1 (1), 1-7. doi: 10.22201/igg.terradigitalis.2017.1.8.71

- Moreno, C. (2001). Manual de métodos para medir la biodiversidad. Xalapa, México: Editorial universitaria.

- Moss, M (2001). Landscape Ecology Applied in Land Evaluation. Development and Conservation. ITC. 81/IALE, MM-1.

- Muñoz, A., Luna, R., Percino, R., Horvath, A. (2004). Anfibios y Reptiles de la Reserva de la Biosfera El Triunfo. En M. A. Pérez, N. Martínez, A. Hernández, A. Arreola (Eds.). La Reserva de la Biosfera El Triunfo, tras una década de conservación (pp. 137-150). Tuxtla Gutiérrez, México: Universidad de Ciencias y Artes de Chiapas. 
- Naveh, Z. (1994). Biodiversity and landscape management. In K. Kim and R. Weaver (Coord.). Biodiversity and Landscapes. A Paradox of Humanity (187-207). New York, United States of America: Cambridge University Press.

- Palacio, J. L. (2013). Geositios, geomorfositios y geo parques: importancia, situación actual y perspectivas en México. Investigaciones Geográficas, (82). 24-37.

- Pérez, M. A., Gómez, H. (2010). Definiciones, importancia y origen. En M. A. Pérez, C. Tejeda, S. Evodia (Coords.). Los bosques mesófilos de montaña en Chiapas (pp. 19-35). Tuxtla Gutiérrez, México: Universidad de Ciencias y Artes de Chiapas.

- Priego, A., Moreno, P., Palacio, J. L., López, J., Geissert, D. (2003). Relación entre la heterogeneidad del paisaje y la riqueza de especies de flora en cuencas costeras del estado de Veracruz, México. Investigaciones Geográficas, (52), 31-52.

- Priego, A., Morales, H., Guadarrama, C. (2004). Paisajes físico-geográficos de la cuenca Lerma-Chapala. Gaceta Ecológica, (71), 11-22.

- Priego, A. Campos, M., Bocco, G., Ramírez, L. (2013). Relationship between landscape heterogeneity and plant species richness on the Mexican Pacific coast. Applied Geography, (40), 71-178. doi: 10.1016/j.apgeog.2013.02.013

- Priego, A., y Esteve, M. A. (2017). Análisis de la complejidad y heterogeneidad de los paisajes de México. Papeles de Geografía, (63), 7-20. doi: 10.6018/geografia/2016/259991

- Ramírez, L., Priego, A., Bollo, M., Castelo, D. (2016). Potencial para la conservación de la geodiversidad de los paisajes del Estado de Michoacán, México. Perspectiva Geográfica, 21 (2), 321-344. doi: 10.19053/01233769.5856

- Romme, W. (1982). Fire and Landscape Diversity in Subalpine Forest of Yellowstone Nacional Park. Ecological Monographs, 52 (2), 199-221. http://www.jstor.org/stable/1942611

- Sarukhán, J., Koleff, P., Carabias, J., Soberón, J., Dirzo, R., Llorente, J., Halffter, G., González, R., March, I., Mohar, A., Anta, S., De La Maza, J. (2009). Capital natural de México. Síntesis: conocimiento actual, evaluación y perspectivas de sustentabilidad. D.F., México: Offset Rebosán.

- Shaw, D. and Olfield, J. (2007). Landscape science: a Russian geographical tradition. Annals of the Association of American Geographers, 97 (1), 111-126. doi: 10.1111/j.1467-8306.2007.00526.x

- Semenov, Y., and Snytko, V. (2013). The 50th Anniversary of the Appearance of V.B. Sochava's Fist Article on the Geosystem. Geography and Natural Resources, 34 (3), 197-200. doi: 10.1134/S1875372813030013

- Semenov,Y (2014). Landscape Geographical Support of the Ecological Policy of Nature Management in Regions of Siberia. Geography and Natural Resources, 35 (3), 208-112. doi: 10.1134/S1875372814030020

- Semenov, Y. (2017). Landscape planning: The applied branch in complex physical geography. Geography and Natural Resources, 38 (4), 319-323. doi: 10.1134/S1875372817040023

- Snacken, F., and Antrop, M. (1983). Structure and Dynamics of Landscape Systems. In J. Drdos (Ed.), Landscape Synthesis (pp. 10-30). Veda, Slovak: Slovak Academy of Sciences.

- StatSof, Inc. (2011). Statistica, ver. 10. Tulsa, United States of America.

- Turner, M. (1989). Landscape Ecology: The effect of pattern on process. Annual review of ecology and systematics, 20 (1), 171-197.

- Turner, M., and Gardner, R. (1991). Quantitative Methods in Landscape Ecology. New York, United States of America: Springer-Verlag.

- Turner, M., Gardner, R., O’ Neill, R. (2001). Landscape Ecology in Theory and Practice: Pattern and Process. New York, United States of America: Springer-Verlag.

- Villafuerte, D. (2013). Desarrollo y migración: una reflexión sobre el campo chiapaneco. En Comisión Nacional para el Conocimiento y Uso de la Biodiversidad (CONABIO) y Gobierno del Estado de Chiapas (Eds.), La biodiversidad en Chiapas: Estudio de Estado (pp. 89-95). D.F., México: Editorial Impresora Apolo.

- Villafuerte, D. (2015). Crisis rural, pobreza y hambre en Chiapas. LiminaR. Estudios Sociales y Humanísticos, XIII (1),13-28.

- Villalobos, G. (2013). El contexto físico y su importancia para la preservación de la Biodiversidad en Chiapas. En Comisión Nacional para el Conocimiento y Uso de la Biodiversidad y Gobierno del Estado de Chiapas (Eds.), La biodiversidad en Chiapas: Estudio de Estado (pp. 27-40). D.F., México: Editorial Impresora Apolo.

- Villaseñor, J. L. (2010). El bosque húmedo de montaña en México y sus plantas vasculares: catálogo florístico-taxonómico. D.F., México: Comisión Nacional para el Conocimiento y Uso de la Biodiversidad - Universidad Nacional Autónoma de México. 


\section{Sobre los autores}

Horacio Morales Iglesias

Profesor-Investigador Titular del Centro de Investigación en Gestión de Riesgos y Cambio Climático de la Universidad de Ciencias y Artes de Chiapas. Licenciado, Maestro y Doctor en Geografía por la Universidad Nacional Autónoma de México. Ha publicado diversos artículos sobre Geografía del Paisaje y Riesgos. Ha impartido 53 Cursos sobre Geomorfología, Cartografía, Introducción al Ordenamiento Territorial, Riesgo por Inestabilidad de Laderas, Evaluación de Cuencas. Ha dirigido cinco Tesis de Licenciatura.

Ángel Guadalupe Priego Santander

Investigador Titular del Centro de Investigaciones en Geografía Ambiental de la Universidad Nacional Autónoma de México. Licenciado en Geografía por la Universidad de La Habana, Cuba. Maestro en Ciencias en Ecología Aplicada por el Instituto de Ecología y Sistemática de Cuba. Doctorado en Ecología y Manejo de Recursos Naturales por el Instituto de Ecología, A. C. de Xalapa, Veracruz, México. Ha publicado 82 productos primarios. Ha impartido 40 Cursos de Posgrado en Cuba, México y Bolivia. Ha dirigido cuatro Tesis de Licenciatura; 13 de Maestría en Ciencias y cuatro de Doctorado en Ciencias. 